\title{
Leakage Resistance Envelopes of API 8 Round Casing Connections using FE Analysis
}

\author{
J. C. M. Uribe ${ }^{a}$ \\ R. Carrazedo ${ }^{a}$ (D)
}

\section{A. T. Beck ${ }^{a^{*}}$}

a Departamento de Engenharia de Estruturas, Escola de Engenharia de São Carlos, Universidade de São Paulo. Av. Trabalhador São-carlense 400, São Carlos, SP, Brasil. E-mails: juanmant.lla@gmail.com, carrazedo@gmail.com, atbeck@sc.usp.br

*Corresponding author

http://dx.doi.org/10.1590/1679-78255350

\begin{abstract}
Leakage resistance of casing connections can be evaluated by extremely expensive testing procedures. Although testing is required for connection validation, significant amount of resources can be saved by complementing testing with Finite Element (FE) analysis. In this regard, a broadly accepted criterion to characterize leaks in FE simulation is still required. This paper proposes an objective and accurate criterion to characterize leakage resistance of casing connections in axisymmetric FE simulation. The criterion is based on stab flank contact pressures and stab flank engaged length parameters. The criterion is tested in application to API 8 Round LTC connections (5 1/2 J55 14lb/ft), and confronted with test results. Leakage envelopes are obtained considering make-up torque and tensile axial loads. The influence of taper on connection sealability is also investigated. The long term goal of the investigation is to derive probabilistic leakage envelopes of casing connections considering manufacturing tolerances, effect of thermal cycles, and seal ovalization due to bending during assembly.
\end{abstract}

\section{Keywords}

Finite element analysis; threaded connections; leakage resistance; sealability; seal integrity;

\section{Introduction}

Failure of casing and tubing of underground wells has the potential to produce severe environmental damage and huge economic loss. Field failures of casing and tubing are most often related to connections, rather than to pipe body. The most common problems with casing connections are casing wear during drilling due to drillstring contact, connection back-out due to heavy drillstring-casing interaction, connection fatigue due to inadequate support and drillstring-casing interaction [37], leaks due to improper make-up, connection jump-out due to inadequate make-up or cross-threading, connection galling due to excessive make-up [28]. In the experience of PETROBRAS, connection seal ovalization due to bending during assembly is a commonly observed problem. Hence, proper modelling of connection strength and leak resistance is fundamental for safe well operation.

Modern regulation for oil and gas exploration in marine environments demands for quantitative risk analysis of offshore installations [29]. In parallel, there is a recent trend for reliability-based design of wells and well casing, in particular under HTHP (High Temperature High Pressure) conditions [30-33]. Probabilistic models of pipe body burst and collapse strengths have been significantly studied, as reported in [34]. However, well casing reliability cannot be achieved unless probabilistic envelopes of connection resistance are developed [35], in view of the impact of connection failures in the field. Results presented herein are part of a long-term goal to develop probabilistic leakage 
envelopes of casing connections considering manufacturing tolerances, effect of thermal cycles, and seal ovalization due to bending during assembly. In this paper, a leakage criterion is proposed, considering the effects of make-up, axial load and internal pressure. Taper influence is also investigated.

The remainder of this paper is organized as follows. In Section 2 a brief literature review on FE modelling of leakage in casing connections is presented. FE modelling assumptions are presented in Section 3, and the proposed leakage criterion is presented in Section 4. Numerical results are presented in Section 5, and confronted with existing test data. Results are discussed in Section 6, and concluding remarks are presented in Section 7.

\section{Review of FE modelling of leakage in casing connections}

Numerical analysis of threaded connections can be made using 3D or axisymmetric models. 3D models representing the helix geometry are very accurate for simulating effects of make-up torque $[1,36]$. However, 3D models are also computationally expensive. Axisymmetric models are much cheaper to evaluate, and appear most often in the published literature. Axisymmetric models can simulate axisymmetric loading, such as axial load, internal and external pressures, and also some non-axisymmetric loads, such as make-up torque and bending [3-5]. Axisymmetric models are known to overestimate stress concentration factors [2,3].

This study addresses leakage resistance of casing connections using axisymmetric FE models. Estimation of leakage resistance is a complex process. Murtagian et al. [6] observed large influence of thread compound on the evolution of leakage rates in premium connections. Temperature is known to modify seal compound properties, and to induce axial stresses that impact sealability [7-9]. Also, it is recognized that nature of contained fluids affects sealing behavior $[10,11]$. FE analysis is not able to replicate all of these effects. However, previous studies have attempted to predict sealability of API round threaded connections based on thread metal to metal contact behavior.

This research uses API 8 Round LTC connections as study objects, as geometries are widely available. Figure 1 shows an axial cut of an API 8 round LTC connection. Figure 2 shows in greater detail the elements of an API 8 round thread. API 8 round connectors have two sealing mechanisms: flank contact pressures, which produce a metal to metal seal; and dope seal, which fills the clearance between fillet crest and root. Figure 3 illustrates the effect of tensile load $T$ on API 8 round threads. Literature distinguishes two types of fillet flanks, depending on their response to tensile loads: load flank and stab flank. In the load flank, relative sliding occurs. In the stab flank, contact pressure decreases and separation can occur. In round threaded connections, it was believed that leakage occured due to increase of clearance between crest and root. However, Asbill et al. [12] noticed that clearance growth due to axial load is negligible, in comparison to reduction in Stab Flank Contact Pressure (SFCP). Thus, further studies have used SFCP to estimate connector sealability by FE analysis.

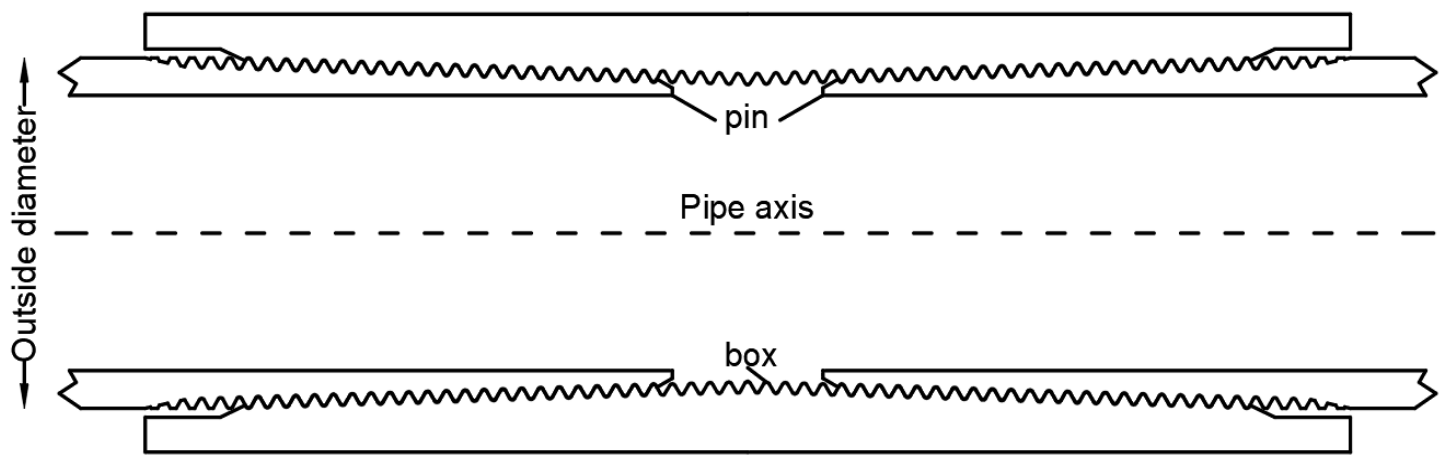

Figure 1. Longitudinal cut view of API 8 round connection. 


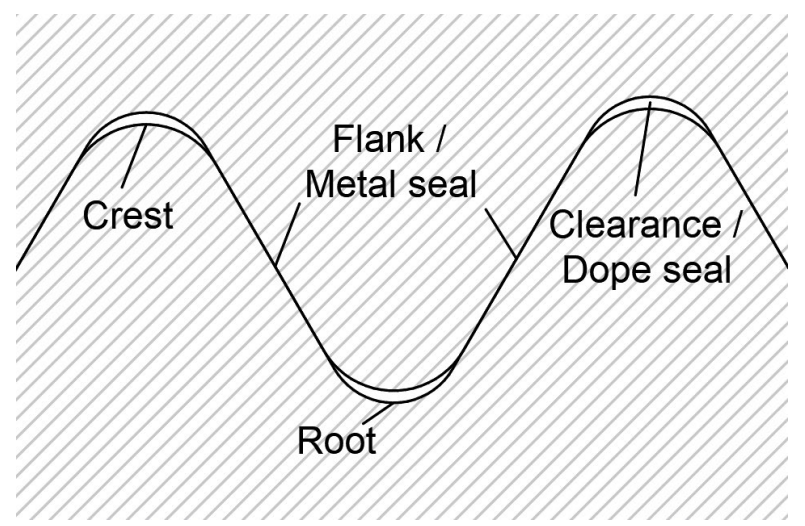

Figure 2. API 8 round thread elements.

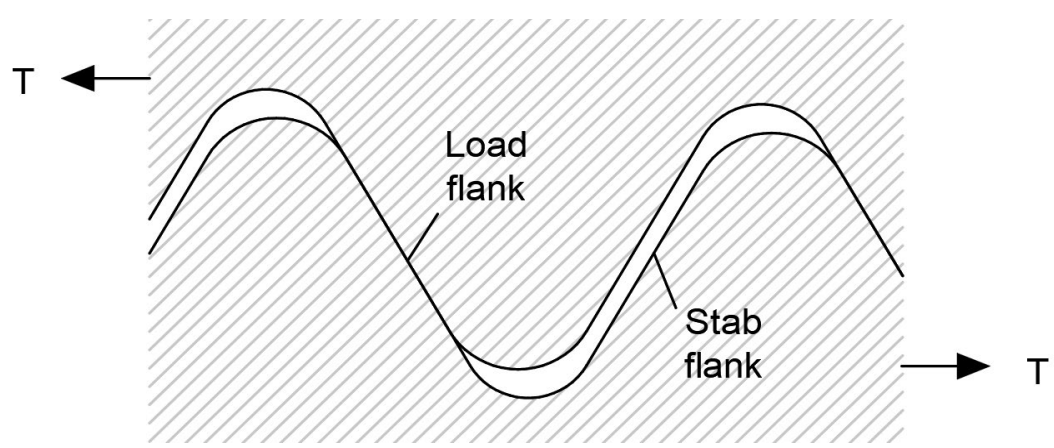

Figure 3. Effect of tensile load on API 8 round thread.

Several studies have proposed different criteria based on SFCP to define leakage resistance. Figure 4 illustrates two proposed criteria to determine if fluid penetration occurs: 1) fluid penetration occurs if fluid pressure exceeds SFCP; 2) fluid penetration occurs if SFCP is zero [13]. Schwind et al. [14,15] suggested two parameters to quantify sealability: 1) average pressure on the stab flank and 2) average pressure on stab flank normalized by the internal pressure. Assanelli et al. [10] use those criteria to predict sealability, reproducing via FE analysis results of capped-end tests. The authors [10] found poor relations between the proposed leakage criteria and test results.

For leakage analysis, it is fundamental to consider the effects of make-up, tensile axial loads, internal pressure and localized material plasticity. Effect of these loads on SFCP values is well documented in literature. Make-up establishes the initial thread contact pressures. Internal fluid pressure increases SFCP due to pin expansion over box. Axial tensile loads reduce SFCP, hence also reducing connection sealability. These observations contrast with API 5C3 recommendations for leakage resistance estimation [16]. API recommendations only consider effects of make-up torque, neglecting effects of axial loading and material plasticity, known to be relevant for leakage resistance [15].

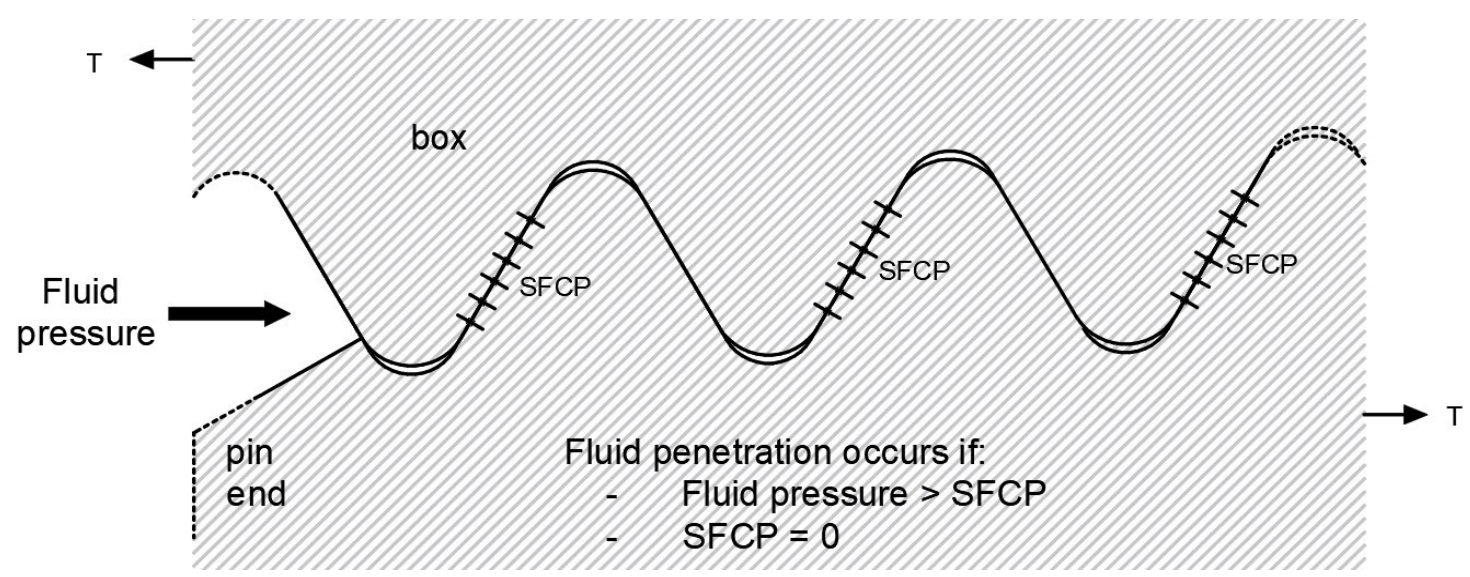

Figure 4. Fluid pressure penetration criteria. 
Loading sequence also influences sealability $[13,15]$. Studies recommend the following load sequence: make-up, followed by axial load, and finally internal pressure. This load sequence replicates service conditions. Studies show that internal pressure loading before traction, or simultaneous fluid pressure and traction application (as in capped-end tests), overestimates leakage resistance. Overestimation derives from the rise of SFCP due to internal pressure, which translates into better seal response.

Since seal of API 8 Round connector is axial load dependent, leakage resistance should be expressed by capacity envelopes. Figure 5 illustrates a schematic leakage capacity envelope. It is expected that fluid pressure resistance be reduced, as axial load increases. Schwind et al. [15] estimated leakage envelopes by evaluating SFCP from plane elasticity considerations, and employed linear regression to correct predictions with FE analysis. However, the authors [15] procedure for estimating leakage envelopes does not involve a well-defined leakage criterion, nor specify which value of SFCP over the engaged length defines leakage resistance.

Schwind et al. [15] suggested the Stab Flank Engaged Length (SFEL) as a parameter to quantify leakage resistance. Loss of SFEL induces leakage, because it opens the helix path, where fluid penetrates. Schwind et al. [15] considered loss of seal when SFEL drops below a critical value, defined by testing. Hence, there is no closed-form recommendation to define the critical SFEL value.

Engaged contact length and average contact pressures have been used to evaluate leakage in metal-to-metal shoulder seals of premium connectors [17], where good agreement with test results was observed [6]. However, there is no generally accepted criterion in the literature to predict leakage resistance envelopes for API round threaded connectors, where metal-to-metal seal is provided at the threads. In this study, a criterion is proposed to evaluate leakage resistance of API 8 Round connectors through axisymmetric FE analysis. The criterion uses SFCP and SFEL parameters to predict leakage resistance. Effect of taper mismatch on leakage envelopes is also estimated. Results obtained with the proposed leakage criterion are confronted with available test results.

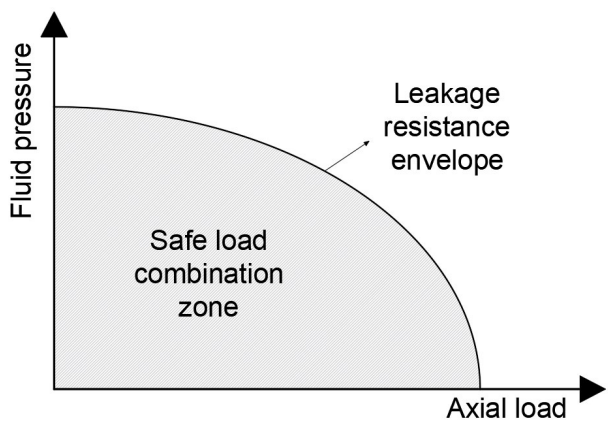

Figure 5. Schematic leakage capacity envelope of API 8 Round connector.

\section{FE modelling assumptions}

This paper addresses leakage resistance of API 8 Round connections using axisymmetric FE models. Connection geometry is taken from API $5 B$ and API $5 C T[19,20]$ specifications. Finite element modelling and simulations are performed in the SIMULIA ABAQUS [18] software. Figure 6 shows the mechanical model of the API 8 Round connection. Axial load is simulated as pressure applied at pipe end.

Nonlinear static analysis is considered. Non-linearities arise from material behavior (yielding), thread surface contact and large deformations. Make-up, axial load and internal pressure are considered for model qualification purposes. For leakage evaluation purposes, only make-up and axial load are considered. Make-up is simulated by means of interference, using contact elements. Interference is consequence of the horizontal advance of the pin towards the box, as make-up turns are applied, following hand tight assembly.

Interference between pin and box, $\delta$, is calculated from Equation 1, where $N$ is the number of turns, $P$ is the pitch and $T$ is the thread taper [21]:

$\delta=N P T / 2$ 


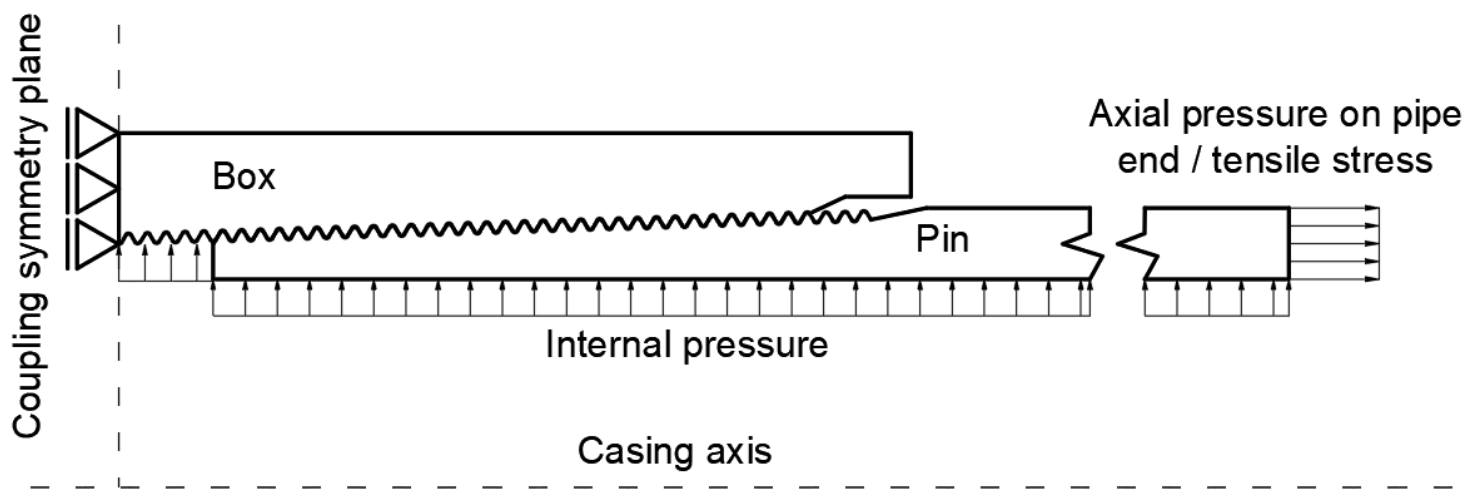

Figure 6. Mechanical model of the API 8 round connection.

Slave and master surfaces define the interaction between pin and box in the threaded region. The contact algorithm restricts surface adhesion and penetration. Coulomb friction model defines contact tangential behavior. $A$ friction coefficient of 0.02 is assumed [10]. The penalty method imposes contact constraints in the numerical solution. The contact model allows finite sliding and separation. Large deformations occur in pin and box [17]; hence, geometrical nonlinear effects must be considered.

Two materials are considered in the study: L80 and J55 steels [22, 23]. An elastic-plastic constitutive model determines material behavior. Young's modulus is equal to $207 \mathrm{GPa}$ and Poisson's ratio is 0.29. The Von Mises yield criterion is used to control steel plastic behavior. Multiaxial isotropic hardening is considered, defined by the multilinear relation between plastic strains and true stress, as illustrated in Figure 7.

Figure 8 a shows the full FEA model of an API 8 round connector. Casing is long enough to ensure no end effects. Figure $8 \mathrm{~b}$ shows details of the finite element mesh employed. Mesh is refined at threads to obtain better local effect representation. FEA models are meshed with quadrilateral axisymmetric linear finite elements with reduced integration (CAX4R). In addition, triangular linear axisymmetric finite elements (CAX3) are used. Possible hourglass effects due to use of linear quadrilateral finite elements were found to be negligible. The validation model (for API 8 Round LTC 9 5/8 L80 connection) uses a total of 50920 elements; 32995 for the pin and 17925 for the box. The leakage study model (API 8 Round LTC 5 1/2 J55) uses 57569 elements for case 1A, 54945 elements for case 1B and 53951 elements for case $3 \mathrm{~A}$ (cases to be described). A complete convergence study was not performed; however, contact pressures were found to be stable w.r.t. a less refined mesh.

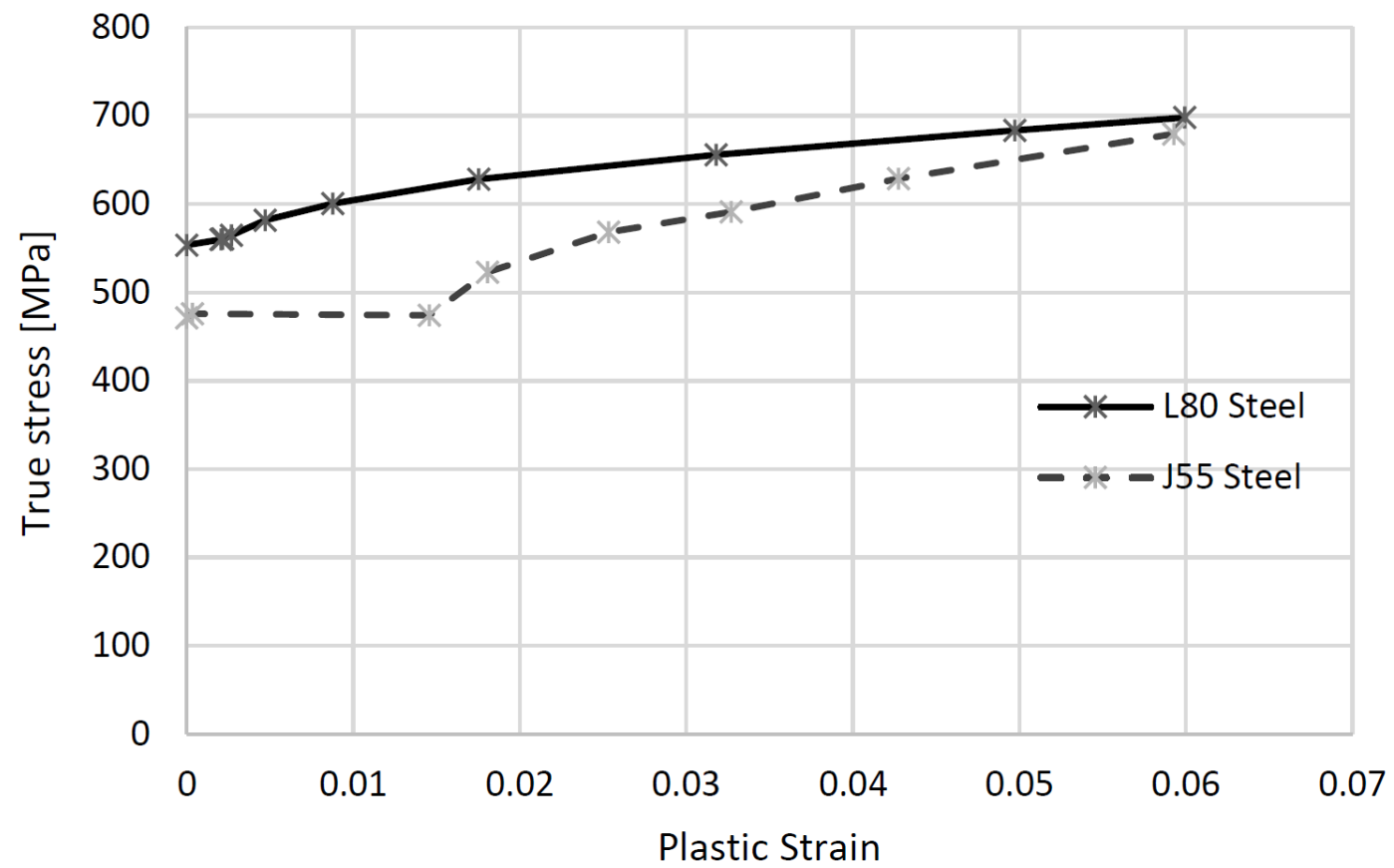

Figure 7. L80 and J55 steels true stress-strain curves. 


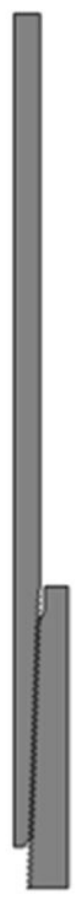

a) Full model

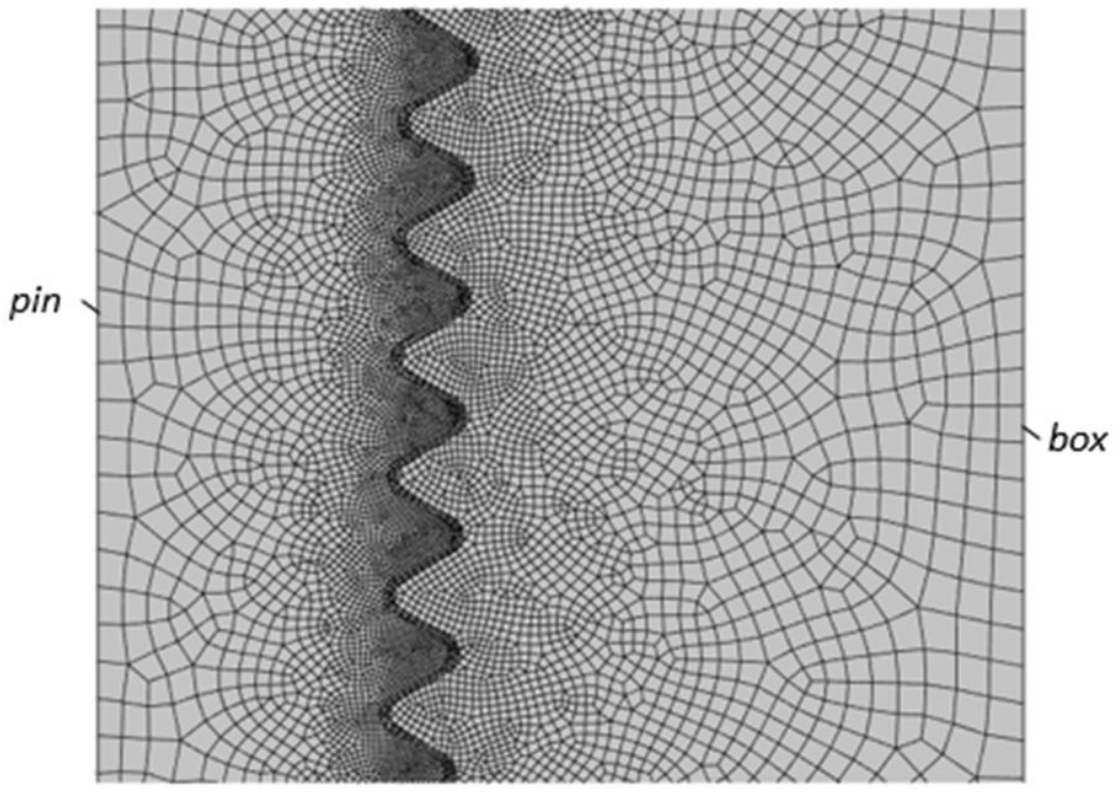

b) Mesh detail

Figure 8. Full model and mesh detail.

\section{Proposed leakage criterion}

Make-up contact between threads establishes the initial flank pressure state. Previous research shows that tensile axial load increases load flank contact pressures, and reduces stab flank contact pressures. On the other hand, internal pressure increases both load and stab flank contact pressures, due to pin expansion over the box.

In this study, leakage resistance analysis is performed under the assumption that the state of stab flank pressures, after make-up and axial loading, defines the maximum allowable internal pressure.

Two parameters are used to establish leakage resistance: Stab Flank Engaged Length (SFEL) and Stab Flank Contact Pressure (SFCP). SFEL is the sum of stab flank thread length for which SFCP is greater than zero, over the length of the connection. Loss of stab flank engaged length happens when all stab flank pressures are zero. When SFEL is zero, all stab flanks separate. The resulting clearance leads to formation of an helical path, which leads to leakage failure. Hence, leakage resistance envelopes are limited by the axial load that causes loss of SFEL.

For SFEL greater than zero, leakage resistance is controlled by SFCP. Leakage resistance estimation starts from make-up SFCP condition. Figure 9 illustrates the process of leak resistance envelope estimation. For a fixed value of axial load, the FE model yields discrete values of flank surface contact pressures over the engaged length, as shown in Figure 9a. Our leakage criterion is stated as:

"Leakage resistance of the API 8 round connector, for a fixed axial load, is given by the average of stab flank contact pressures near the pin end, but neglecting the SFCP at the first pin end thread."

Therefore, the mean SFCP value and the corresponding axial load define a discrete point in the leakage envelope, as shown in Figure 9b. For full envelope estimation, tensile load is varied from zero (i.e. from make-up) to the load that causes loss of SFEL.

We propose that SFCP at first pin end thread be neglected in mean SFCP computation. Large variability is observed in SFCP at the first engaged thread, counted from pin end. This variability results from bias in the choice of axisymmetric plane. It is caused by evolvement, over the helix, of the first engaged thread, from incomplete to full shape. Thus, leaving the first thread out in mean SFCP computation prevents from considering extreme pressure values which do not effectively contribute to sealability. 

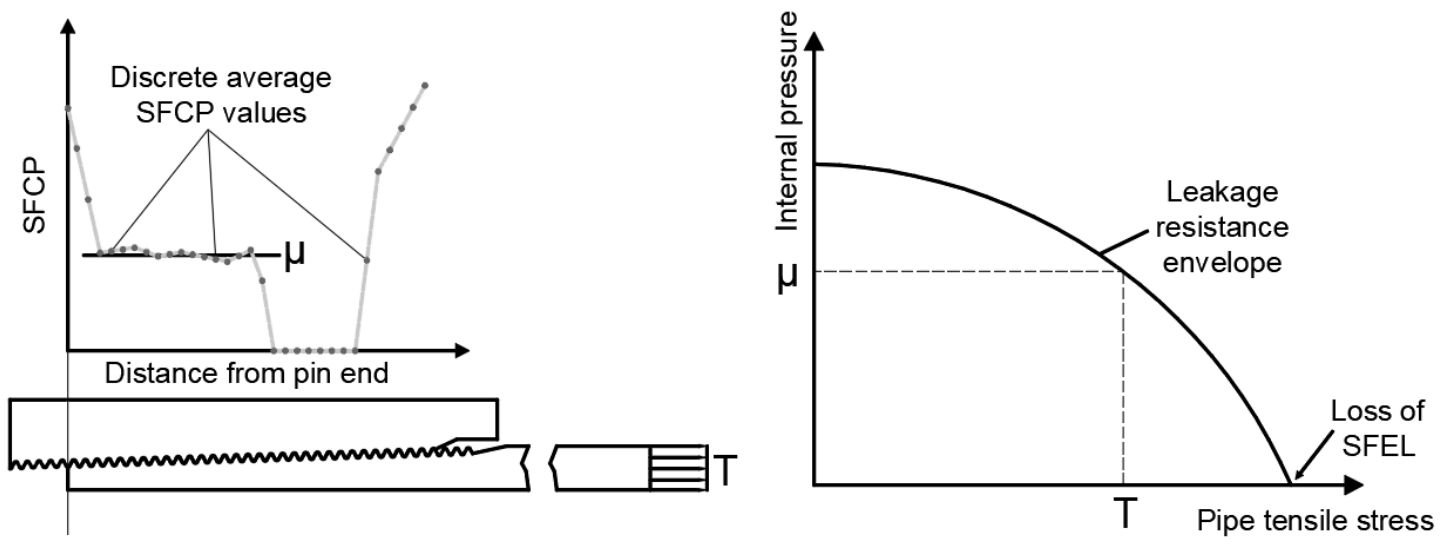

Figure 9. Leakage capacity estimation process.

\section{Results}

\subsection{Finite element modeling validation.}

For FE modelling validation, the API 8 Round LTC $95 / 8$ L80 $47 \mathrm{lb} / \mathrm{ft}$ connection is simulated. The connection is modelled using nominal geometry. Three load cases are considered, as detailed in Table 1: only make-up, make-up plus tensile load, make-up plus tensile load plus internal pressure. Results are validated by comparing average load flank pressures over connection length, with those evaluated by Assanelli et al. [24] and Allen et al. [25].

Results of average load flank pressures as function of pin end distance are shown in Figure 10, for the three load cases described in Table 1. As can be observed, the FE model employed herein produces-load flank pressures which show good agreement with the cited references. Further, Figure 11 illustrates the plastic zones, for each load case. Results agree with those in reference [25].

Table 1. Load cases for FEA model qualification.

\begin{tabular}{cc}
\hline Load case 1 & Make-up of 3.5 turns from hand tight position \\
\hline Load case 2 & Make-up of 3.5 turns from hand tight position \\
& + Pipe tensile stress of 344.737 MPa \\
Load case 3 & $\begin{array}{c}\text { Make-up of } 3.5 \text { turns from hand tight position } \\
+ \text { Pipe tensile stress of } 344.737 \mathrm{MPa} \\
\end{array}$ \\
& + internal pressure of $47.37 \mathrm{MPa}$ \\
\hline
\end{tabular}




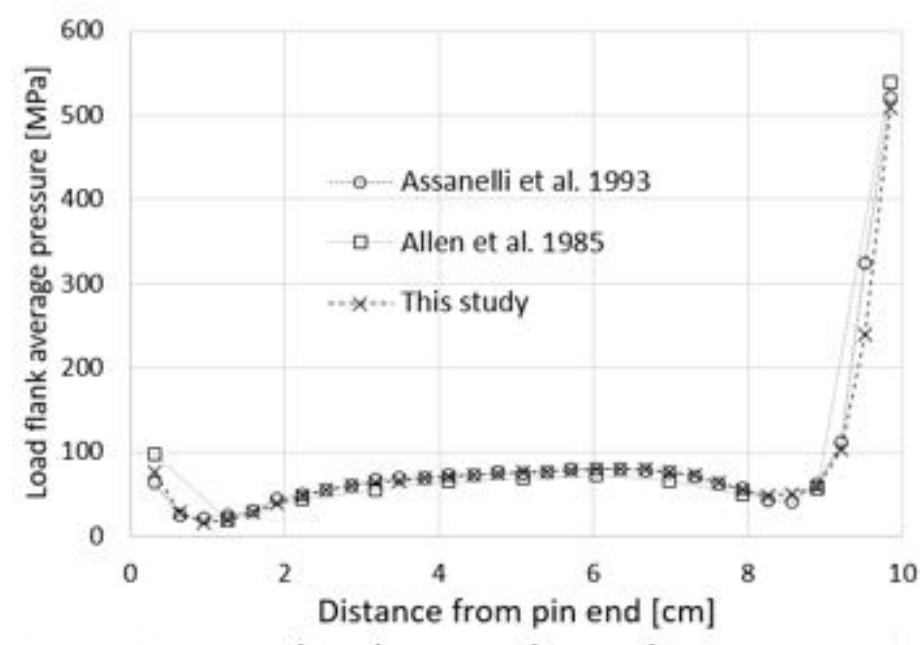

a) Load Case 1: make-up only.

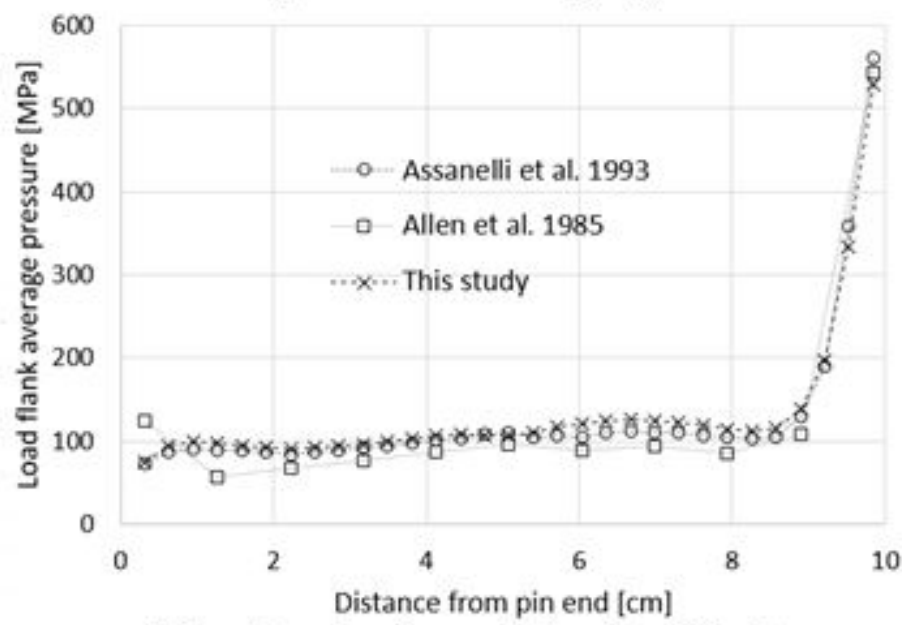

b) Load Case 2: make-up plus tensile axial load.

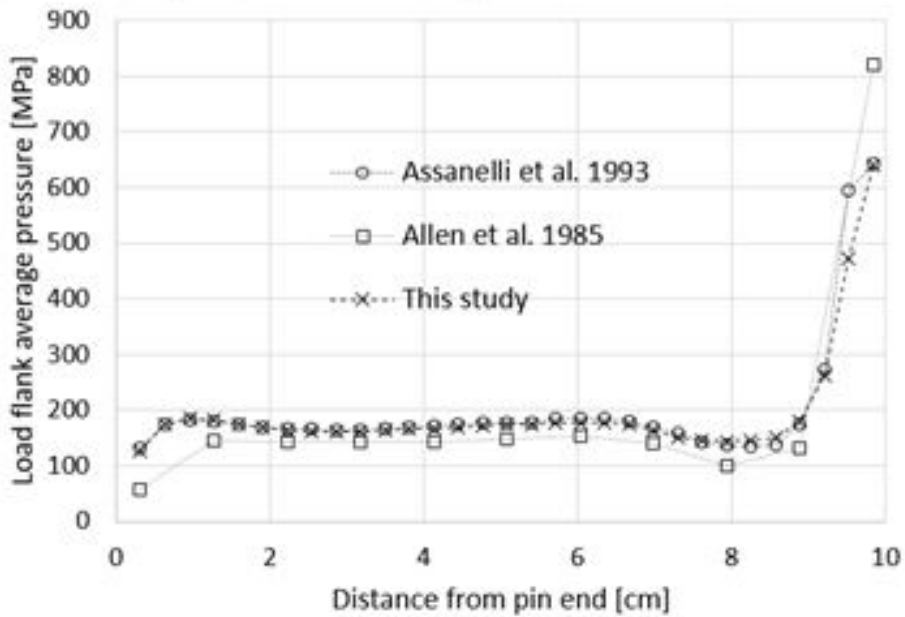

c) Load Case 3: make-up plus tensile axial load plus internal pressure.

Figure 10. Load flank pressures, API 8 round $95 / 8 \mathrm{~L} 8047 \mathrm{lb} / \mathrm{ft}$ casing connection. 


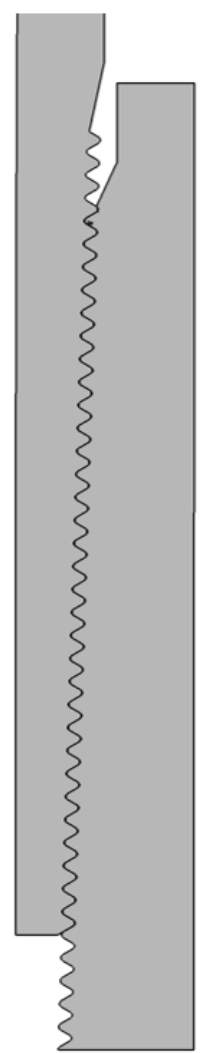

a) Load case 1

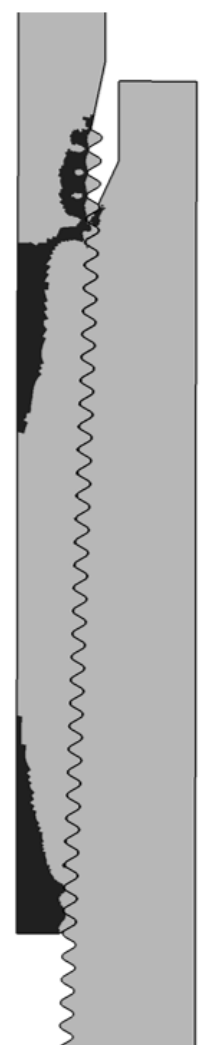

b) Load case 2

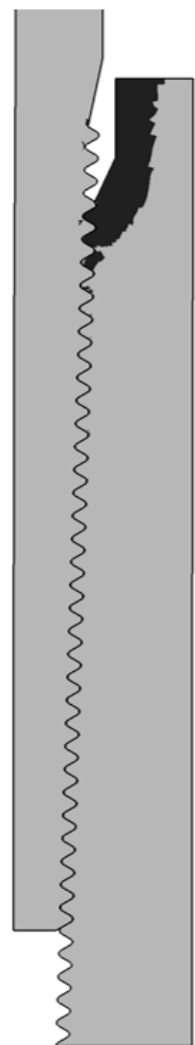

c) Load case 3

Figure 11. Plastic zones (in black) in three load cases, API 8 round $95 / 8 \mathrm{~L} 8047 \mathrm{lb} / \mathrm{ft}$ casing connection.

\subsection{Leakage criterion evaluation}

Stab flank contact pressures in terms of pin end distance are shown in Figure 12, for the API 8 round 9 5/8 L80 47 $\mathrm{lb} / \mathrm{ft}$ casing connection, for the three load cases described in Table 1. As expected, tensile axial load reduces SFCP and SFEL. After axial loading, the average value of flank pressures near pin-end is just over the expected upcoming internal pressure. After internal pressure loading, SFCP increase, as expected. However, stab flank pressure at first thread is zero. Hence, pressure penetration is likely to occur at the pin end. Pressure penetration does not evolve over the thread, because stab flank pressures over the rest of engaged length are higher than internal pressure. Hence, one can assume that sealability is preserved, although this is clearly a limit situation.

According to the proposed criterion, the seal is at the brink of being broken, because the average SFCP near pinend is just over the expected upcoming internal pressure. After axial load, a leak is just about to occur; after internal pressure loading, sealability is improved. The example reveals a problem for leakage resistance estimation through FE analysis: evaluation of SFCP after internal pressure loading leads to a perception of seal improvement. We believe that improved sealability due to internal pressure is a limitation of the model, which does not account for the actual fluid, and for eventual fluid-structure interaction. To address this problem, we understand that leakage resistance should be determined from the average value of flank pressures near pin-end, prior to internal pressure loading. 


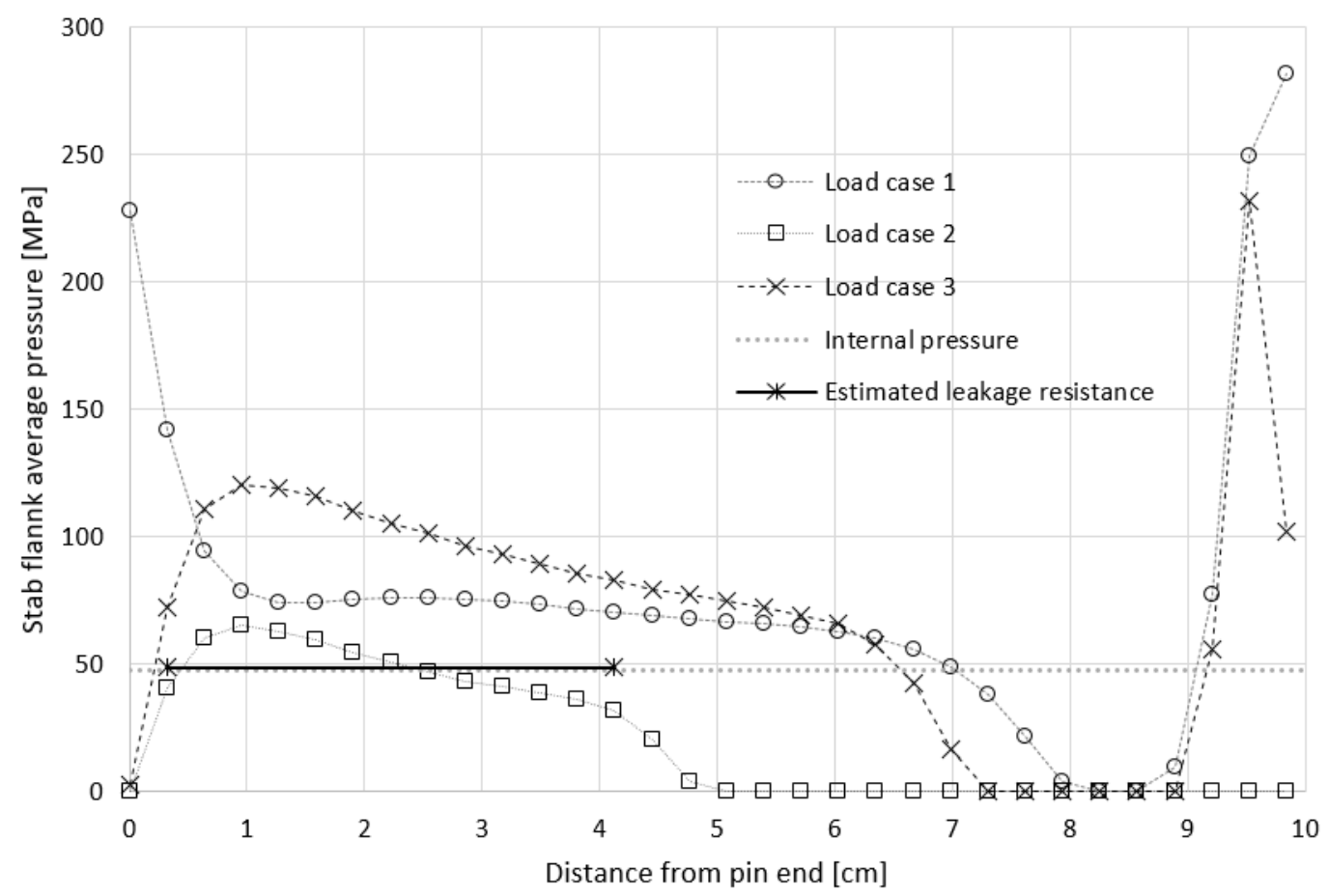

Figure 12. Stab flank contact pressures, API 8 round $95 / 8$ L80 $47 \mathrm{lb} / \mathrm{ft}$ connection.

\subsection{Leakage envelope estimation}

For estimation of leakage resistance envelope, the API 8 Round LTC $5 \quad \frac{1}{2} \quad$ J55 $14 \mathrm{lb} / \mathrm{ft}$ casing connection is considered, as for this casing test results are available. The resistance envelope is evaluated by considering different pin and box taper combinations, following recommendations of API 5C5 [26]. The pin and box taper combinations, and torque values considered, are described in Table 2.

This leakage analysis aims to construct resistance envelopes of specimens $1 \mathrm{~A}, 1 \mathrm{~B}$ and $3 \mathrm{~A}$, defined in Table 2, in terms of pin and box taper combination, and torque value. Table 3 shows taper values considered, which correspond to tolerance limits [19]. Make-up for all test cases is 3 turns from hand-tight position, which provides the basic powertight make-up for this connection [27].

Table 2. Pin and box taper combinations, and torque, for leakage resistance envelope evaluation.

\begin{tabular}{cccc}
\hline & \multicolumn{3}{c}{ FE Specimen Parameters } \\
\cline { 2 - 4 } & 1A & 1B & 3A \\
\hline Pin taper & Fast & Slow & Nominal \\
Box taper & Slow & Fast & Nominal \\
\hline
\end{tabular}

Table 3. Taper values for leakage resistance envelope evaluation.

\begin{tabular}{rc}
\hline Slow taper & 0.0599 \\
\hline Nominal taper & 0.0625 \\
Fast taper & 0.0677 \\
\hline
\end{tabular}

Stab flank contact pressures, as a function of distance from pin end, are shown in Figures 13 to 15 , for specimens $1 \mathrm{~A}, 1 \mathrm{~B}$ and $3 \mathrm{~A}$, respectively, and for different values of pipe tensile stress. The figures also show average values of SFCP, used as measure of leak resistance. It is clear from these figures that average SFCP and SFEL, hence also leakage resistance, are reduced as tensile axial load increases. It is also clear that specimen configuration $1 \mathrm{~A}$ is the most detrimental to leakage resistance. 

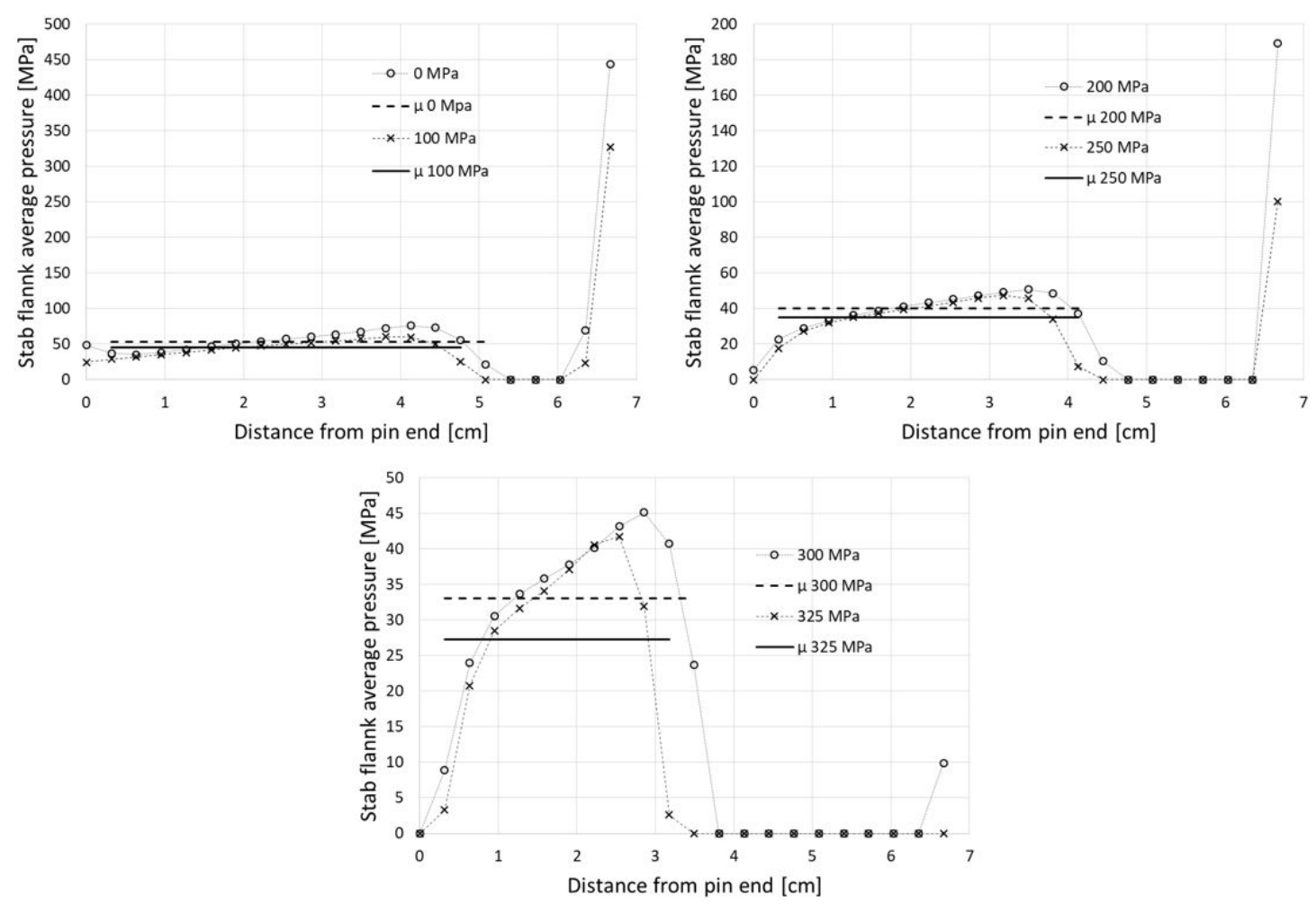

Figure 13. SFCP and estimated leakage resistance, specimen $1 \mathrm{~A}$.
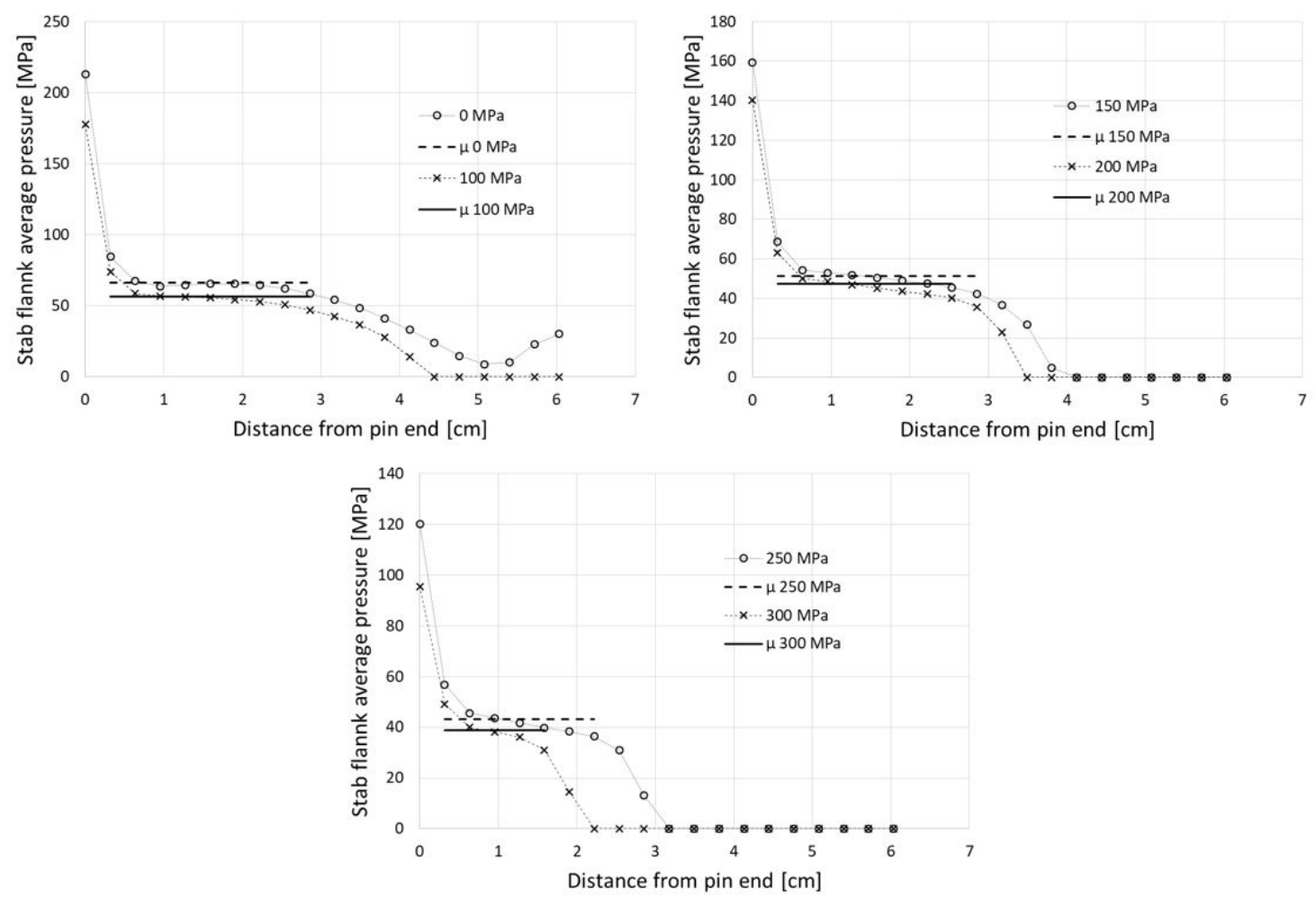

Figure 14. SFCP and estimated leakage resistance, specimen 1B. 

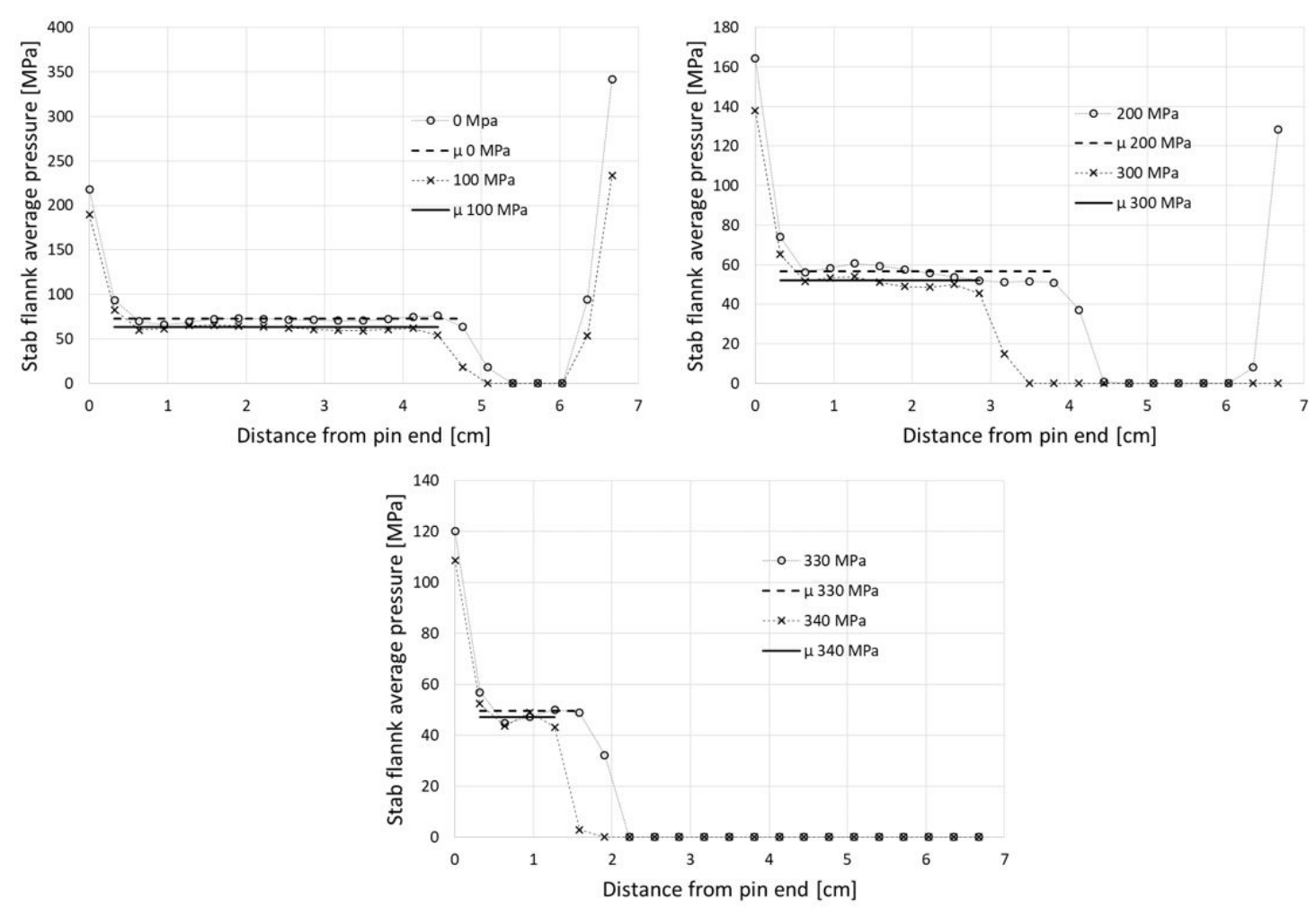

Figure 15. SFCP and estimated leakage resistance, specimen $3 \mathrm{~A}$.

Stab flank engaged lengths (SFEL) are compared in Figure 16, in terms of applied axial load, for the three specimen configurations considered herein. It is clear in this figure that configuration $1 \mathrm{~B}$ is more critical for SFEL, although configuration $1 \mathrm{~A}$ produces smaller average values of SFCP.

Figures 17 to 19 show the leakage resistance envelopes obtained in this study, for specimens $1 \mathrm{~A}, 1 \mathrm{~B}$ and $3 \mathrm{~A}$, respectively. Results are compared with the envelopes of Schwind et al. [15], and also with experimental results presented in ref. [15] for the API 8 Round LTC 5 1/2 J55 14lb/ft casing connection. Although only three experimental results are available for each specimen configuration, it is clear that our numerical analysis, and the proposed leakage criterion, lead to better estimates of leakage resistance, in comparison to [15]. In general, our leakage predictions are better than [15] for larger values of tensile load. The loss of SFEL criterion leads to abrupt drop in leakage resistance for limit tensile loads.

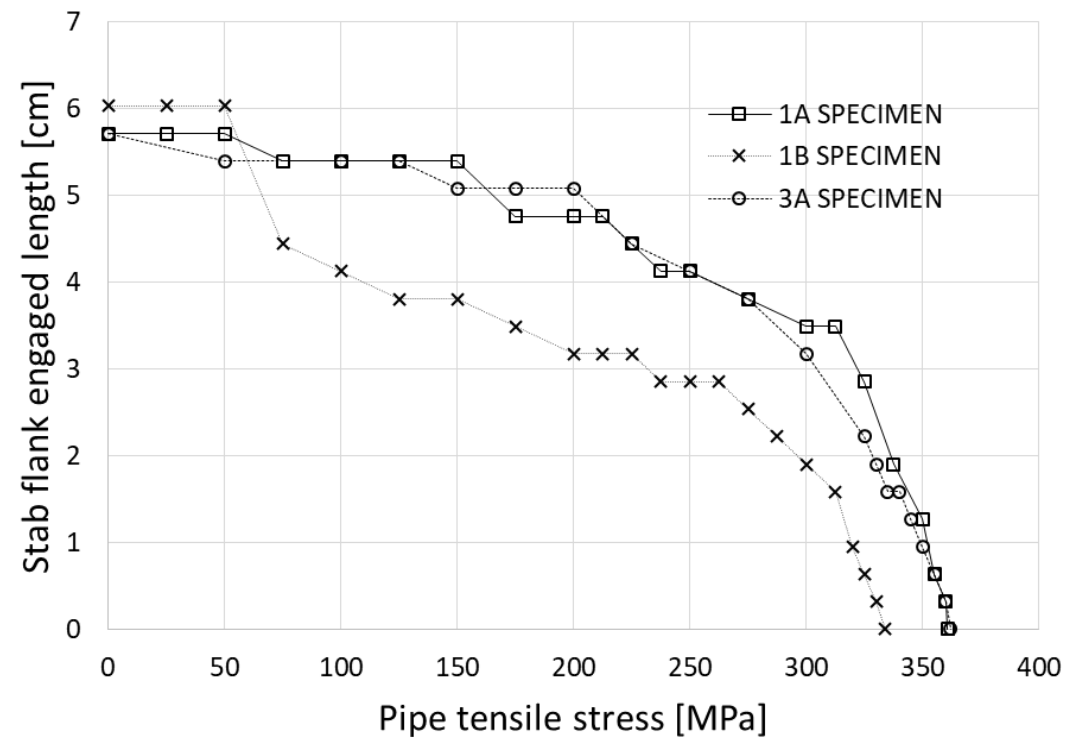

Figure 16. Stab flank engaged length as function of tensile axial stress. 


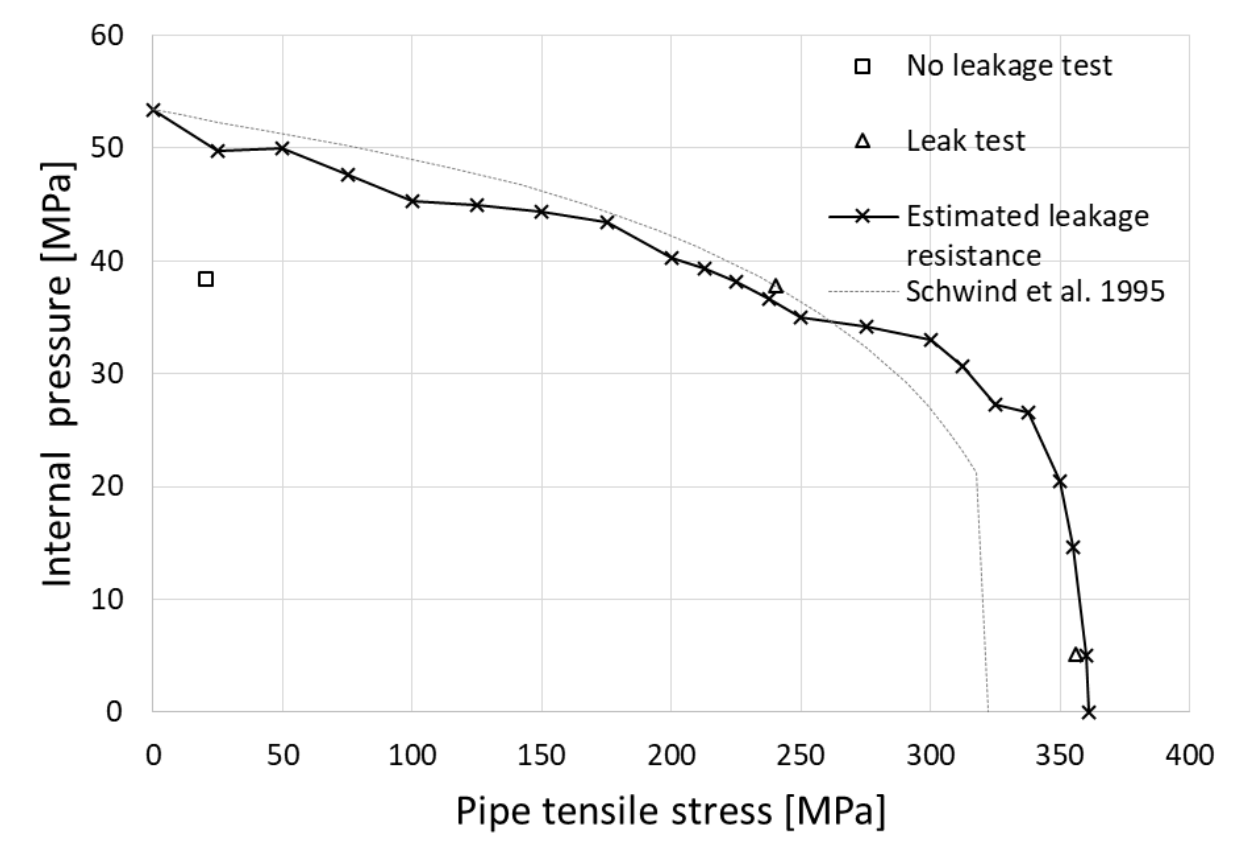

Figure 17. Leakage resistance envelope, specimen $1 \mathrm{~A}$.

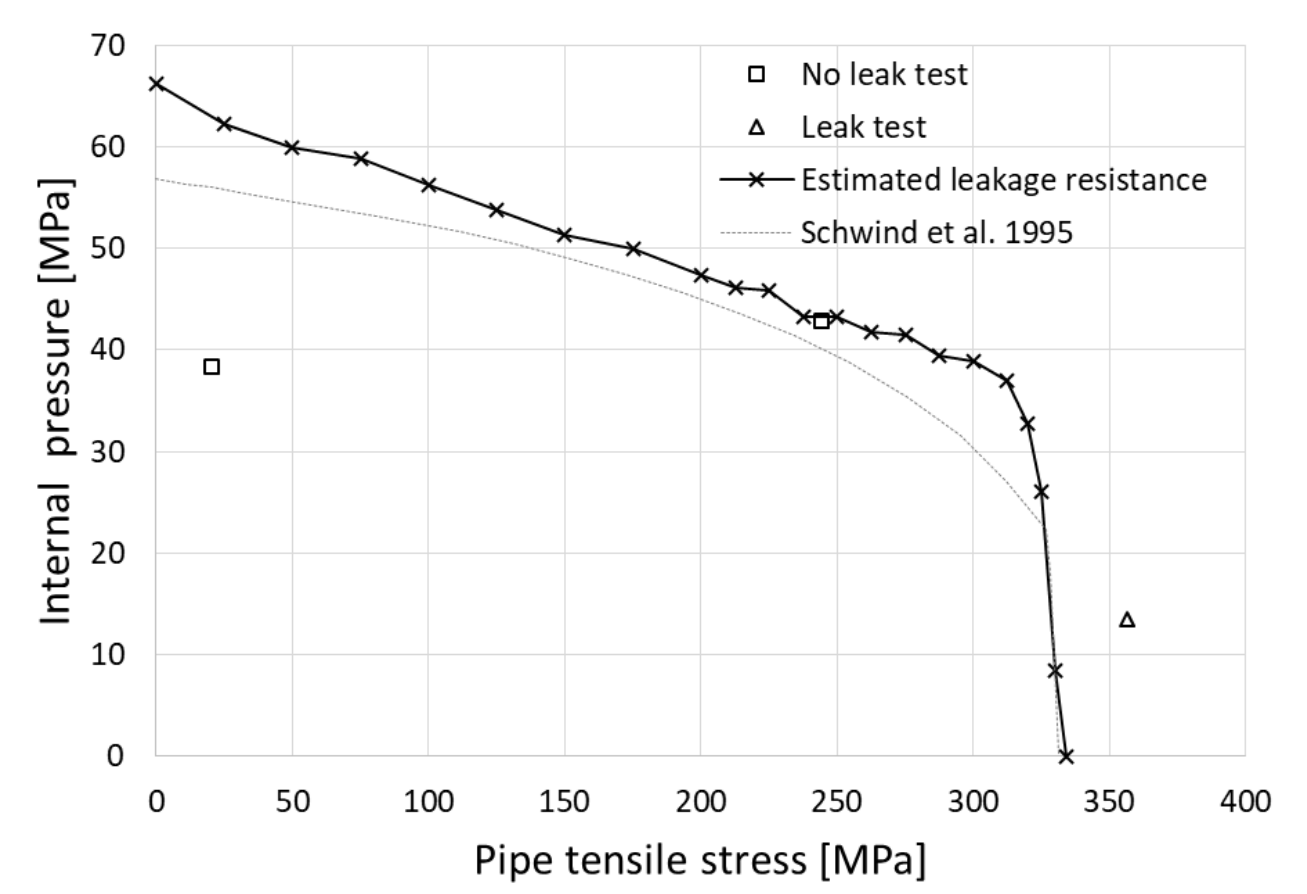

Figure 18. Leakage resistance envelope, specimen $1 \mathrm{~B}$. 


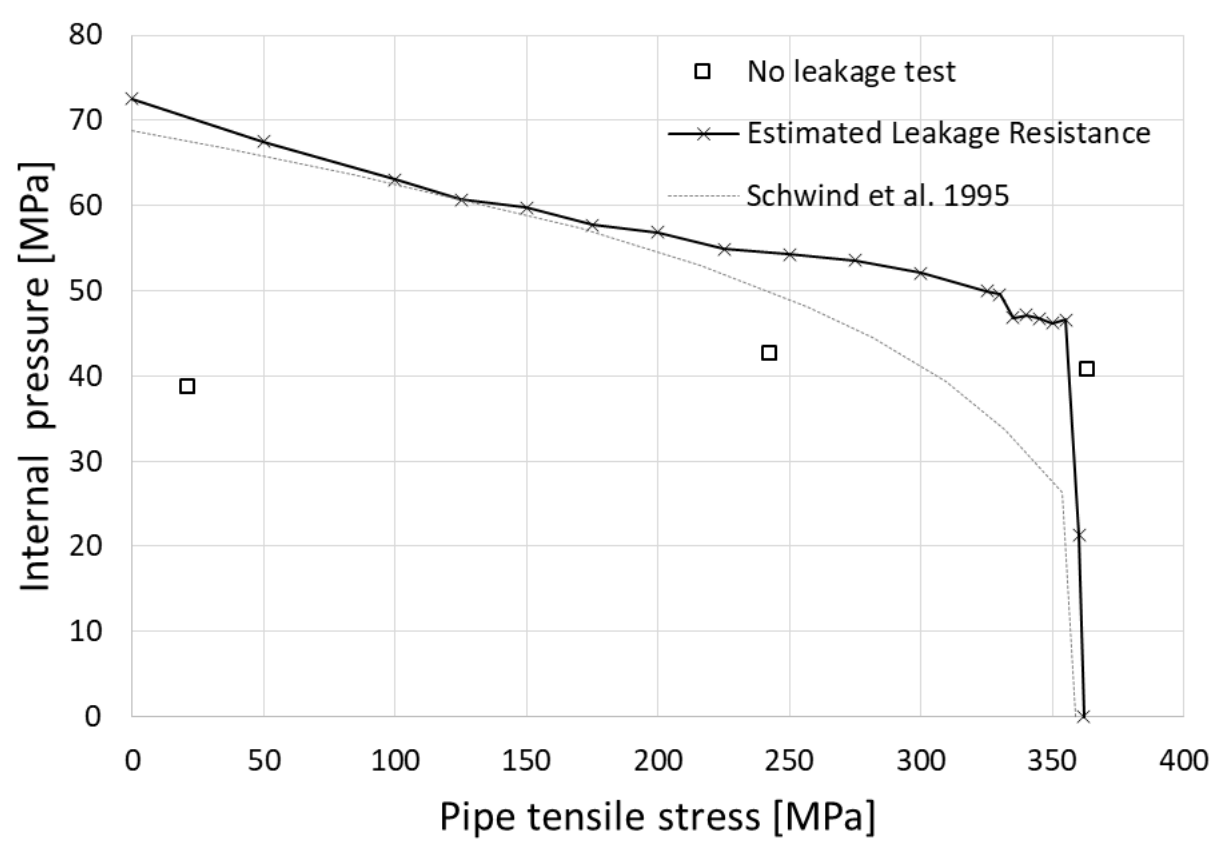

Figure 19. Leakage resistance envelope, specimen 3A.

\section{Discussion}

Nominal taper connection delivers the best sealability, as should be expected. Our results show that mismatched tapers lead to lower leakage resistance. For specimens 1B and 3A, SFCP values oscillate around the mean (estimated resistance) with little deviation. Thus, specimens $1 \mathrm{~B}$ and $3 \mathrm{~A}$ leakage resistance envelope carry small uncertainty associated with mean SFCP computation. SFCP values for specimen 1A show larger deviation around the estimated mean; thus the estimated seal envelope can be said to carry larger uncertainty related to mean SFCP estimation. For both matched and mismatched taper cases, the deviation of SFCP from mean value increases, as axial loads increase. Good quality control is advised for field assemblies, to ensure matching taper geometry, so that leakage prediction can be made with greater confidence.

The proposed leakage prediction criterion has the advantage of relying only on FE analysis results and in simple mean value calculations. The proposed FE modelling resembles the same loading sequence used in tests [15]. The good agreement with test results shows that the proposed modelling assumption, and the proposed leakage criterion, can accurately predict leakage resistance for API 8 Round LTC connections. It remains to be verified if modelling assumptions and leakage criterion remain valid for other, perhaps proprietary, connection geometries.

We discourage application of the methodology proposed herein to evaluate sealability on capped end tests. This observation is made with reference to the study of Assanelli et al. [10], where poor agreement between FE calculated SFCP values and capped end test results are found. This may be a consequence of the improvement in SFCP following internal pressure loading, which is believed to be misleading in terms of seal improvement (see section 5.2).

In connection sealability tests, fluid pressure is applied gradually. In this case, fluid pressures could increase SFCP values, improving sealability. In service conditions, however, sudden rise of fluid pressure can occur, and thread contact pressures may not be sufficient to warrant connection seal integrity. Moreover, in service condition tensile axial loads are permanent, due to casing column weight. Therefore, we believe our predictions to be good estimation of sealability for cases of continuous axial loading and low-pressures, and for cases of instantaneous internal pressure loading. Therefore, we recommend the methodology proposed herein for estimating leakage resistance of API 8 round threaded connectors in service conditions.

As this study is based on FE analysis, some variables that are known to influence sealability cannot be considered. This includes characteristics of sealing compound, nature of the pressurization fluid, sealing compound extrusion, temperature effects, and the implications of field loading and unloading conditions. 


\section{Concluding remarks}

In this paper, a FE analysis methodology and a leak criterion were proposed for estimation of leakage resistance envelopes of API 8 Round LTC connections. The methodology is based on axisymmetric FE models, and considers nonlinear effects of material plastification, surfaces interaction by contact elements and large deformation. The analysis considers effects of make-up torque and tensile axial loading, which must be applied in this order. The proposed leak criterion is based on stab flank engaged length (SFEL) and in stab flank contact pressures (SFCP). Modelling assumptions include neglecting the beneficial effect of internal pressure loading in SFCP. The proposed leak criterion is given by the average of SFCP near the pin end, but neglecting SFCP at the first pin end thread. Loss of SFEL determines the maximum tensile load that can be withstand by the connection before leak failure. Comparison with test results shows that the proposed modelling assumption, and the proposed leakage criterion, provide accurate prediction of leakage resistance envelopes. Taper variations were also studied: it was shown that nominal taper delivers the best seal performance; whereas the combination of fast pin and slow box, is the worst in terms of leak resistance.

\section{Acknowledgements}

The authors acknowledge indirect funding of this research project by means of surplus from PETROBRAS contract 0050.0089855.14.2. The last author acknowledges funding by CNPq (Brazilian National Council for Research, grant $\mathrm{n}$. 306373/2016-5).

\section{References}

[1] Chen F, Di QF, Wang WC, Zhu WP, Wang MJ, Shen ZJ. The Reliability Evaluation of Threaded Connections in Challenging Drilling by Three-Dimensional Finite Element Analysis. Adv Mater Res 2013;690-693:2831-9.

doi:10.4028/www.scientific.net/AMR.690-693.2831.

[2] Shahani AR, Sharifi SMH. Contact stress analysis and calculation of stress concentration factors at the tool joint of a drill pipe. Mater Des 2009;30:3615-21. doi:10.1016/j.matdes.2009.02.022.

[3] Tafreshi A, Dover W. Stress analysis of drillstring threaded connections using the finite element method. Int J Fatigue 1993;15:429-38. doi:10.1016/0142-1123(93)90490-H.

[4] Bahai H. A parametric model for axial and bending stress concentration factors in API drillstring threaded connectors. Int J Press Vessel Pip 2001;78:495-505. doi:10.1016/S0308-0161(01)00060-6.

[5] Yuan G, Yao Z, Wang Q, Tang Z. Numerical and experimental distribution of temperature and stress fields in API round threaded connection. Eng Fail Anal 2006;13:1275-84. doi:10.1016/j.engfailanal.2005.11.006.

[6] Murtagian GR, Fanelli V, Villasante JA, Johnson DH, Ernst HA. Sealability of Stationary Metal-to-Metal Seals. J Tribol 2004;126:591. doi:10.1115/1.1715103.

[7] Xie J, Tao G. Analysis of Casing Connections Subjected to Thermal Cycle Loading. Abaqus Users' Conf RI, USA 2010:1-16.

[8] Badicioiu M, Teodoriu C. Sealing Capacity of API Connections - Theoretical and Experimental Results. SPE Drill Complet 2009;24:96-103.

[9] Tao G, Xie J. Analytical Evaluation of Casing Connections for Thermal Well Applications. SPE Heavy Oil Conf 2013:11-3.

[10] Assanelli AP, Xu Q, Benedetto F, Johnson DH, Dvorkin EN. Numerical/Experimental Analysis of an API 8-Round Connection. J Energy Resour Technol 1997;119:3-10.

[11] API. API 5C5: Recommended Practice on Procedures for Testing Casing and Tubing Connections. Am Pet Inst $2002 ; 2002$.

[12] Asbill WT, Pattillo PD, Rogers WM. Investigation of API 8 Round Casing Connection Performance- Part III : Sealability and Torque. Energy Resour Technol 1984;106:144-52.

[13] Schwind BE, Wooley GR. New Findings on Leak Resistance of API 8-Round Connectors. SPE Prod Eng 1989.

[14] Schwind BE. Equations for Leak Resistance of API 8-Round Connectors in Tension. Offshore Technol Conf 1987.

[15] Schwind BE, Chappell JF, Katsounas AT, Services SE. Threaded Connection Limit State Equations for Use in LRFD Tubular Design. Offshore Technol Conf 1995;2:1-4. doi:10.4043/7939-MS. 
[16] API. API TR 5C3. Technical Report on Equations and Calculations for Casing, Tubing, and Line Pipe Used as Casing or Tubing. Am Pet Inst 2008;2007.

[17] Dvorkin EN, Toscano RG. Finite element models in the steel industry. Comput Struct 2003;81:575-94. doi:10.1016/S00457949(02)00403-0.

[18] Dassault Systèmes Simulia. Abaqus Analysis User's Manual V6.14. 2014.

[19] API. API 5B : Specification for Threading, Gauging and Thread Inspection of Casing, Tubing, and Line Pipe Threads. Am Pet Inst 2008.

[20] API. API 5CT: Specification for Casing and Tubing. Am Pet Inst 2011.

[21] Chen S, Li Q, Zhang Y, An Q. Finite element analysis of tooth load distribution on P-110S conic threaded connections. Int J Press Vessel Pip 2011;88:88-93. doi:10.1016/j.ijpvp.2011.01.004.

[22] Irawan S, Bharadwaj AM, Temesgen B, Karuppanan S, Abdullah MZB. Effect of wear on the burst strength of I-80 steel casing. 3rd Int Conf Mech Eng Res 2015;012027. doi:10.1088/1757-899X/100/1/012027.

[23] Morita N, Shiozawa S. Stability Analysis of Casings During Plastic Deformation. SPE Deep Drill Complet Conf 2014:10-1.

[24] Allen MB, Schwind BE, Wooley GR. Investigation of leak resistance of API 8-Round Connectors in tension. Final report for API PRAC Project 84-53. 1985.

[25] Assanelli AP, Dvorkin EN. Finite Element Models of OCTG Threaded Connections. Comput Struct 1993;47:725-34. doi:10.1016/0045-7949(93)90354-G.

[26] Institute AP. API 5C5 Recommended Practice for Evaluation Procedures for Casing and Tubing Connections. Second Edi. 1996.

[27] API. API 5C1: Recommended Practice for Care and Use of Casing and Tubing. Am Pet Inst 1999.

[28] Payne ML, Sathuvalli UB, Crabtree SR, 1998: Select Topics and Applications of Probabilistic OCTG Design, SPE Applied Technology Workshop on Risk-based design of Well Casing and Tubing, SPE International.

[29] Skogdalen JE, Vinnem JE, 2012: Quantitative risk analysis of oil and gas drilling, using Deepwater Horizon as a case study, Rel. Eng. \& System Safety 100, 58-66.

[30] Adams AJ, Hodgson T, 1999: Calibration of Casing/Tubing Design Criteria by use of Structural Reliability Techniques, SPE Drilling \& Completion 14, 21-27.

[31] Erivwo O, Adeleye O, 2012: Narrow Margin Drilling in Deepwater: Solutions Concepts, SPE Deepwater Drilling and Completion Conference, SPE International.

[32] Hinton A, 1998: Will Risk Based Casing Design Mean Safer Wells?, SPE Applied Technology Workshop on Risk-based design of Well Casing and Tubing, SPE International.

[33] Dedenoula AD, Iyamu IE, Adeleye OA, 2003: Stochastic Approach to Kick Tolerance Determination in Risk Based Designs, SPE Annual Technical Conference and Exhibition, SPE International.

[34] ISO 10400, 2011: Petroleum and natural gas industries -Equations and calculations for the properties of casing, tubing, drill pipe and line pipe used as casing or tubing.

[35] Valigura GA, Talin A, 2005: Connections for HPHT Well Application and Connection Leak Probability, SPE High Pressure / High Temperature Sour Well Design Workshop, SPE International.

[36] Cavaco MAM, Viotti MR, Albertazzi Jr. GA, 2018: Pipeline Stress Analysis Through Stress Function Fittings, Latin American Journal of Solids and Structures 15(9), e92.

[37] Wittenberghea JV, Pauwa JD, Baetsa PD, Waelea WD, Wahaba MA, Roeck GD, 2010: Experimental determination of the fatigue life of modified threaded pipe couplings, Procedia Engineering 2 (1), 1849-1858. 